\title{
Clinicians and the coronial system: ability of clinicians to recognise reportable deaths
}

\author{
R D Start, Y Delargy-Aziz, C P Dorries, P B Silcocks, D W K Cotton
}

\begin{abstract}
Objective-To assess the ability of clinicians to recognise deaths which require referral to the coroner.

Design-Postal questionnaire consisting of 16 fictitious case histories, 14 of which contained a clear indication for referral to the coroner.

Setting-Large teaching hospital. Coroner's office.

Subjects-200 clinicians from general medical and surgical firms and senior staff of the local coroner's office (two coroner's officers and the two deputy coroners).

Main outcome measures-Number of correct assessments on questionnaire.

Results-The mean recognition score for the clinicians was 9.11 (range 3-14) with no difference between the clinical grades. All of the coroner's senior staff recorded maximum recognition scores of 16.

Conclusions-The study highlights several features of the coronial system which are poorly understood by clinicians and provides the basis for an initiative to improve the medicolegal education of all clinicians.
\end{abstract}

\section{Introduction}

All citizens including doctors have a duty under common law to report deaths in some circumstances to the coroner.' Few people, apart from registrars of births, deaths, and marriages, have a specific statutory obligation to report deaths and so in practice most cases are reported by doctors and the police. In 1991, 182000 deaths were reported to coroners in England and Wales. ${ }^{2}$ Natural disease or death associated with medical treatment represent about $80 \%$ of all cases referred to the coroner and are usually reported by doctors.

Failure by doctors to recognise reportable cases may create administrative difficulties and unnecessary distress for bereaved relatives and medical colleagues. Other cases may evade medicolegal investigation altogether because they are not recognised as death due to unnatural causes. All doctors should be aware of the various categories of cases which require referral to the coroner, but to our knowledge there have been no reports in which this knowledge has been formally tested.

Traditional methods of assessing knowledge that use questionnaires often fail to consider the context in which the knowledge is required. ${ }^{34}$ This can be achieved in part by the use of fictitious case histories, which allow the clinician to show his or her knowledge in a form of role enactment. ${ }^{56} \mathrm{We}$ used this approach to assess the ability of hospital doctors to recognise cases which should be reported to the coroner.

\section{Subjects and methods}

Two hundred hospital doctors from general medical and surgical firms were sent a postal questionnaire consisting of 16 fictitious case histories (see appendix for examples). Fourteen of the case histories contained a clear indication for referral to the coroner. After each case history the clinicians were asked if they would report the death to the coroner and to state the reasons for their decision. The decision to report cases was at the sole discretion of the respondents. The questionnaire was also sent to the four local senior coroner's officers and deputy coroners.

One mark was awarded for a correct answer and no marks for an incorrect answer. A correct answer was defined as an appropriate response with clear identification of the indication for referral

\section{Results}

A total of 135 clinicians completed the questionnaire, some after a single reminder. No second reminder was sent. This represented an overall rate of response of $68 \%$. All grades of clinician were represented in the responding sample which comprised 34 consultants, 16 senior registrars, 22 registrars, 32 senior house officers, and 31 house officers. All four of the local coroner's staff participated in the study. The table shows the mean recognition scores for each grade of clinician. There were no significant differences in the mean scores of the different grades of clinician.

Recognition scores of doctors asked to decide whether examples of deaths should be referred to coroner's office according to clinical grade

\begin{tabular}{lccc}
\hline Clinical grade & Mean score & Range & No of staff \\
\hline House officer & $8 \cdot 87$ & $4-12$ & 34 \\
Senior house officer & $9 \cdot 38$ & $5-14$ & 16 \\
Registrar & $8 \cdot 77$ & $3-13$ & 22 \\
Senior registrar & $9 \cdot 75$ & $7-13$ & 32 \\
Consultant & $8 \cdot 85$ & $3-14$ & 31 \\
\hline
\end{tabular}

${ }^{\star}$ Maximum possible score $=16$.

\section{Discussion}

The legal aspects of medicine are usually included in the final stages of the undergraduate medical curriculum. Unfortunately most newly qualified junior doctors are inappropriately exposed to the complexities of death certification and the coronial system before they have gained the necessary practical experience of this important topic in clinical medicine. Further confusion arises as a result of local variations in coroners' practices. Understandably many junior doctors seek advice from senior colleagues, coroner's officers, and pathologists, but such advice can be misleading or incorrect particularly if the clinician fails to recognise and disclose all relevant information.

The experienced local coroner's staff were able to identify all of the reportable cases in this study, whereas clinicians of all grades identified only about half of the same cases. The poor performance of the clinicians suggests that they may regularly fail to refer reportable deaths. Although some of these cases would be detected by other doctors signing cremation forms, by the local registrar of births, deaths, and marriages, and by coroner's officers when contacted for advice, other cases may receive no further investigation. Another disturbing observation is that some senior 
clinicians seem to have less understanding of the coronial system than the junior staff under their supervision. This finding supports the comments from several junior doctors who stated that they had occasionally received incorrect advice from senior colleagues and indicates that clinicians of all grades must be encouraged to participate in postgraduate medicolegal education.

Individual clinicians at all grades showed a variable appreciation of the different categories of cases which should be reported to the coroner. Many were unaware that chronic liver disease due to alcohol is no longer a reportable cause of death. Most, but worryingly not all, clinicians reported the cases involving allegations of negligence, death in police custody, criminal death, suicide, and industrial disease. Deaths resulting from accidents were often unrecognised and many clinicians did not seem to know that all such deaths are reportable to the coroner, no matter how long a time has elapsed between the injury and the death. There was considerable variation in the ability to recognise the different types of accidents, and some seemed to believe that deaths resulting from accidents are reportable only if the accident occurs in suspicious circumstances. Deaths which resulted from road traffic accidents and domestic accidents involving fire were usually reported, and industrial accidents and domestic accidents in which elderly people had fallen were often not reported, particularly if a long time had elapsed between the accident and the death.

The main confusion seemed to be in relation to deaths associated with medical treatment. Individual coroners may have differing requirements with respect to the types of deaths in hospital reported to them. Many coroners, including the coroner in this study, require all deaths that occur within 24 hours of emergency admission to be reported. This is not a legal requirement but a working rule established by many coroners based on the principle that a definite diagnosis often cannot be satisfactorily ascertained during the first day after admission. Clinicians seemed particularly uncertain of their responsibilities when the proposed clinical diagnosis had not been confirmed "beyond doubt" or if patients with established diseases died shortly after readmission.

A similar problem arose when death occurred during medical or surgical procedures including diagnostic investigations. Most clinicians were aware that death under anaesthesia is always reportable and that coroners usually require any death occurring within 24 hours of recovery from anaesthesia to be reported. Clinicians often do not seem to appreciate that reportable deaths include a wide range of circumstances other than surgical operations and anaesthesia. Cases in which some form of medical treatment, including drug treatment, may have contributed to death were often not recognised by clinicians. This time limit is again only a convenient working rule and local variations in the practice of individual coroners may confuse doctors who regularly move between centres.

\section{CONCLUSIONS}

We have highlighted several parts of the coronial system which are poorly understood by clinicians. The interest generated by these observations has enabled the development of a local initiative to improve clinicians' awareness of the various categories of cases that should be reported to the coroner. There are five main components of this initiative.

(1) The legal aspects of medicine, including the coronial system, should continue to form an important part of the undergraduate medical curriculum.

(2) Clinical postgraduate medical education should include medicolegal subjects with regular participation of pathologists and the coroner.

\section{Deaths reportable to the coroner: a brief} guide

Any death should be referred to a coroner if the medical practitioner cannot readily certify death as being due to natural causes within the terms of regulation 51 of the Registration of Births, Deaths and Marriages Regulations 1968. Some of the major categories of death that must be reported are when:

- There is any element of suspicious circumstances or history of violence

- The death may be linked to an accident (whenever it occurred)

- The death may be due to industrial disease or related in any way to the deceased's occupation

- The death is linked with an abortion

- The death occurred during an operation or before full recovery from the effects of anaesthesia or was in any way related to the anaesthesia

- The death may be related to a medical procedure or treatment

- The actions of the deceased may have contributed to his or her own death-for example, self neglect, drug or solvent misuse

- The death occurred in police or prison custody (includes a death from an illness or injury which arose during detention ${ }^{\star}$ )

- The death was within 24 hours of admission to hospital ${ }^{\star}$

- The deceased was detained under the Mental Health Act ${ }^{\star}$

*Desired local practice rather than statutory requirement.

(3) Death certification and referral of cases to the coroner are the responsibility of consultants or senior clinicians and should be delegated to junior doctors only under close supervision. All senior clinicians must be aware of the categories of cases which require referral.

(4) A brief guide to the indications for the referral of cases to the coroner should be regularly circulated to all clinicians (see box).

(5) Clinicians should report all cases about which they are uncertain. Advice is always available from the coroner, coroner's officers, or senior pathologists.

We thank Professor J C E Underwood for the use of departmental facilities and the deputy coroners, coroner's officers, and clinical colleagues who participated in the study.

1 Knight B. Legal aspects of medical practice. Edinburgh: Churchill Livingstone, 1987.

2 Research and Statistics Department, Home Office. Statistics of deaths reported to coroners: England and Wales 1991. Home Office Statistical Bulletin 1992 Apr 15. (Issue 7/92.)

3 Harre R, Secord PF. The explanation of human behaviour. Oxford: Basil Blackwell, 1972.

4 Oppenheim AN. Questionnaire design and attitude measurement. London: Heinemann, 1984.

5 Elstein AS, Shulman LS, Sprafka SA. Medical problem solving, an analysis of clinical reasoning. Massachussets: Harvard University Press, 1978.

6 Start RD, Hector-Taylor MJ, Cotton DWK, Startup M, Parsons MA, Kennedy A. Factors which influence necropsy requests: a psychological Kennedy A. Factors which influence
approach. F Clin Pathol 1992;45:254-7.

(Accepted 28 fanuary 1993)

\section{Appendix}

Examples of case senarios and instructions to recipients of questionnaire

For each of the following case scenarios please decide if the case should be referred to the coroner or one of his officers.

Please note-In each of the following cases you have been provided with all of the relevant information and you are the only clinician responsible for making the decision to refer the case. If you decide to refer the case it is important that you also give your reasons for doing so. 
CASE 1

A 76 year old retired school teacher was admitted with collapse and hypotension. Her medical history included a hiatus hernia and recurrent indigestion. On examination she was hypotensive with generalised guarding and abdominal tenderness. An erect chest $x$ ray picture showed free gas under the diaphragm. A diagnosis of peritonitis secondary to a perforated peptic ulcer was made but her condition did not improve sufficiently to enable surgical intervention and she died four hours after her admission.

\section{Correct answer}

Although the referral of this case is not a statutory requirement, the desired local practice is that any death within 24 hours of admission should be reported.

Answers in study

\begin{tabular}{llc}
\hline Grade & Correct & Incorrect \\
\hline Consultant & 19 & 15 \\
Senior registrar & 11 & 5 \\
Registrar & 11 & 11 \\
Senior house officer & 24 & 8 \\
House officer & 24 & 7 \\
\hline Total & $89(66 \%)$ & $46(34 \%)$ \\
\hline
\end{tabular}

CASE 2

A 29 year old unemployed man was admitted in cardiopulmonary arrest. His relevant medical history included supervision by the psychiatric services with prescribed diazepam, mianserin, and chlorpromazine; he was also known to be a user of amphetamines. Drug overdose was provisionally diagnosed, and extensive resuscitative measures obtained a cardiac output. He was transferred to the intensive care unit and mechanically ventilated. An amphetamine overdose was confirmed from the results of blood screening but his condition did not improve and he died two days later.

\section{Correct answer}

This case must be reported because death results from a drug overdose (possible accident or suicide). This is obviously not a natural cause of death.

Answers in study

\begin{tabular}{llc}
\hline Grade & Correct & Incorrect \\
\hline Consultant & 23 & 11 \\
Senior registrar & 13 & 3 \\
Registrar & 18 & 4 \\
Senior house officer & 25 & 7 \\
House officer & 25 & 6 \\
\hline Total & $104(77 \%)$ & $31(23 \%)$ \\
\hline
\end{tabular}

CASE 3

A 46 year old man was transferred from the spinal injuries unit with severe sacral sores. He had been paraplegic for 15 years since a fall on a building site where he worked as a steel erector. He had recurrent problems with infected sacral sores. A septicaemia was confirmed from the results of blood culture, and he was treated with appropriate antibiotic regimens. He then developed a chest infection and his condition gradually deteriorated. He died 10 days later.

Correct answer

This case should be reported as the death seems to be related to the injuries sustained in an accident. The length of time since the accident is immaterial.

Answers in study

\begin{tabular}{lcc}
\hline Grade & Correct & Incorrect \\
\hline Consultant & 14 & 20 \\
Senior registrar & 7 & 9 \\
Registrar & 7 & 15 \\
Senior house officer & 14 & 18 \\
House officer & 12 & 19 \\
\hline Total & $54(40 \%)$ & $81(60 \%)$ \\
\hline
\end{tabular}

CASE 4

A 72 year old woman suffering from Alzheimer's disease was brought in by her daughter with severe burns after her nightgown was set alight by a cigarette end. Her other relevant medical history included a hemicolectomy for Dukes' stage C carcinoma of the colon. She was admitted to the burns unit with $33 \%$ surface burns and treated with maximum medical treatment. She developed a chest infection and died four days after admission.

\section{Correct answer}

This case must be reported because death is effectively due to the burns suffered in a domestic accident.

Answers in study

\begin{tabular}{llc}
\hline Grade & Correct & Incorrect \\
\hline Consultant & 22 & 12 \\
Senior registrar & 14 & 2 \\
Registrar & 14 & 8 \\
Senior house officer & 26 & 6 \\
House officer & 18 & 13 \\
\hline Total & $94(70 \%)$ & $41(30 \%)$ \\
\hline
\end{tabular}

CASE 5

A 82 year old woman pedestrian was in a road traffic accident and sustained a basal skull fracture, frontal lobe contusions, and contrecoup injury to the occipital lobes of the brain. She was mechanically ventilated and transferred to the intensive care unit, but after a few hours her condition improved and she was able to breathe spontaneously. Her condition did not show any further improvement and despite supportive care, including parenteral feeding, her condition deteriorated, and she died six weeks after admission.

\section{Correct answer}

This death is caused by injuries arising from a road traffic accident and must be reported.

Answers in study

\begin{tabular}{llc}
\hline Grade & Correct & Incorrect \\
\hline Consultant & 29 & 5 \\
Senior registrar & 14 & 2 \\
Registrar & 19 & 3 \\
Senior house officer & 27 & 5 \\
House officer & 21 & 10 \\
\hline Total & $110(81 \%)$ & $25(19 \%)$ \\
\hline
\end{tabular}

CASE 6

A 27 year old unemployed woman was admitted with jaundice after confessing to have taken an overdose of paracetamol five days previously. Investigations showed deranged liver function and abnormal clotting with a raised international normalised ratio. She received full medical treatment to prevent hepatic encephalopathy but developed acute liver failure and renal failure over the next two days. She was admitted to the intensive care unit, but despite maximum treatment she died a week after admission.

\section{Correct answer}

This case must be reported because death results from an overdose of drugs (possible accident or suicide). This is obviously not a natural cause of death.

Answers in study

\begin{tabular}{llc}
\hline Grade & Correct & Incorrect \\
\hline Consultant & 23 & 11 \\
Senior registrar & 14 & 2 \\
Registrar & 16 & 6 \\
Senior house officer & 22 & 10 \\
House officer & 24 & 7 \\
\hline Total & $99(73 \%)$ & $36(27 \%)$ \\
\hline
\end{tabular}

CASE 7

A 72 year old retired policeman with Parkinson's disease was admitted with a fractured right neck of femur after a fall at home. The fracture was fixed operatively, and he made good progress postoperatively and was transferred to a rehabilitation unit for further convalescence. A week later he developed pleuritic chest pain in association with a swollen right calf. A venogram confirmed a small left sided 
pulmonary infarct and he was treated with anticoagulants. Two days later he suffered a cardiopulmonary arrest and despite maximum resuscitative efforts he died.

Correct answer

This is unlikely to be a natural cause of death: the sequence of events begins with a fall, which leads to an operation immobility, and then a pulmonary embolus. The case must be reported. There was no suggestion of an osteoporotic fracture in the history.

Answers in study

\begin{tabular}{lll}
\hline Grade & Correct & Incorrect \\
\hline Consultant & 8 & 26 \\
Senior registrar & 6 & 10 \\
Registrar & 4 & 18 \\
Senior house officer & 9 & 23 \\
House officer & 15 & 16 \\
\hline Total & $42(31 \%)$ & $93(69 \%)$ \\
\hline
\end{tabular}

CASE 8

A 36 year old beautician was admitted with a stab wound

after a domestic disturbance. After immediate resuscitation she underwent an emergency laparotomy and splenectomy. She made a full recovery and was discharged after a week. Two days later she was readmitted with a swollen painful left leg. A venogram confirmed a deep vein thrombosis and she received anticoagulants accordingly. The next day she suffered a cardiopulmonary arrest and died despite resuscitative efforts

\section{Correct answer}

Not only should this case be reported but it would be essential to notify the coroner's officer of the death immediately. There would be a full scale criminal investigation with a possible murder or manslaughter charge.

Answers in study

\begin{tabular}{llc}
\hline Grade & Correct & Incorrect \\
\hline Consultant & 27 & 7 \\
Senior registrar & 14 & 2 \\
Registrar & 18 & 4 \\
Senior house officer & 24 & 8 \\
House officer & 20 & 11 \\
\hline Total & $103(76 \%)$ & $32(24 \%)$ \\
\hline
\end{tabular}

\section{Pre-employment chest radiography for health service staff: who needs it?}

\section{Madan}

\section{Department of}

Occupational Health,

United Medical and Dental

Schools of Guy's and

St Thomas's Hospitals,

St Thomas's Hospital,

London SE1 7EH

I Madan, lecturer

BMF 1993;306:1041-2
Guidelines published by the subcommittee of the Joint Tuberculosis Committee of the British Thoracic Society in 1990 recommend pre-employment Heaf testing of health care workers in regular contact with patients or handling material which may contain tubercle bacilli. ${ }^{1}$ Chest radiography is advised for those with a grade 3 or 4 Heaf reaction and for those with a grade 2 reaction who show no evidence of previous BCG immunisation. However, there are few data on the outcome of pre-employment tuberculin screening in this population to support these guidelines. This study aimed at ascertaining the proportion of prospective employees with strongly positive (grade 3 or 4 ) Heaf reactions and the number requiring chest radiography under the current recommendations.

\section{Subjects, methods, and results}

The guidelines were followed from 1 December 1990 to 31 November 1991 within West Lambeth Health Authority. Consecutive new employees, including students, were screened by a standard Heaf gun; the result was read after seven days. Evidence of previous BCG immunisation was recorded only if the scar was at least $4 \mathrm{~mm}$ in diameter and there was a history of immunisation within the past 25 years. Chest radiography was performed as recommended. In the event of a normal chest radiograph the employee was advised to report any respiratory symptoms over the next year to the occupational health department.

We screened 640 new employees, 428 with evidence of previous BCG immunisation and 212 without. Thirty seven immunised subjects and 15 subjects without evidence of immunisation failed to return for the reading of their tuberculin test. Chest radiography was performed in $212(36 \cdot 1 \%)$ subjects $(95 \%$ confidence interval $32 \cdot 2 \%$ to $40 \cdot 0 \%$ ). No cases of active tuberculosis were detected (table).

The proportions with strongly positive Heaf reactions were not significantly different in those with or without evidence of BCG immunisation $\left(\chi^{2}=2 \cdot 824\right.$, $p>0.05)$. In both groups the proportions of subjects of Asian (Indian subcontinent) and non-Asian origin with strongly positive reactions were not significantly different $\left(\chi^{2}=3.477, p>0.05\right.$ in the immunised group; $\chi^{2}=0.346, p>0.05$ in the group without evidence of immunisation).

Outcome of pre-employment tuberculin screening in 588 new NHS employees according to previous BCG immunisation and ethnic origin

\begin{tabular}{|c|c|c|c|}
\hline \multicolumn{2}{|c|}{$\begin{array}{c}\text { Evidence of } \\
\text { previous BCG } \\
\text { (mean age }=24 \text { ) }\end{array}$} & \multicolumn{2}{|c|}{$\begin{array}{l}\text { No evidence of } \\
\text { previous BCG } \\
\text { (mean age }=26 \text { ) }\end{array}$} \\
\hline $\begin{array}{c}\text { Non-Asian } \\
\text { origin }\end{array}$ & $\begin{array}{l}\text { Asian } \\
\text { origin }\end{array}$ & $\begin{array}{c}\text { Non-Asian } \\
\text { origin }\end{array}$ & $\begin{array}{l}\text { Asian } \\
\text { origin }\end{array}$ \\
\hline
\end{tabular}

\begin{tabular}{lcccc}
\hline Heaf result (grade): & & & & \\
0 & 34 & 2 & 59 & 8 \\
1 & 81 & 22 & 30 & 5 \\
2 & 102 & 33 & $38^{\star}$ & $11^{\star}$ \\
3 & $87^{\star}$ & $15^{\star}$ & $32^{\star}$ & $8^{\star}$ \\
4 & $15^{\star}$ & 0 & $5^{\star}$ & $1^{\star}$ \\
\hline Total & 319 & 72 & 164 & 33
\end{tabular}

${ }^{\star}$ Chest radiography performed.

\section{Comment}

This study suggests that a strongly positive Heaf reaction is a common finding in new employees of West Lambeth Health Authority and that its predictive value for tuberculosis infection in this population, regardless of ethnic origin, is low. A positive tuberculin skin reaction in new NHS employees was also not predictive of an abnormal chest radiograph or of clinical tuberculosis. Similarly, a retrospective casecontrol analysis of abnormal chest radiographs and tuberculin skin reactivity in new employees of another London health district showed no association between the two. ${ }^{2}$ The overall incidence of tuberculosis in England and Wales has fallen substantially this century, ${ }^{3}$ and with the exception of mortuary attendants, the incidence in NHS employees is now no greater than that in the general population. ${ }^{4}$

Though tuberculin skin testing may be valuable in detecting tuberculosis in contact tracing clinics, a positive or strongly positive result has little discriminatory power in diagnosing active tuberculosis in new employees. The value of tuberculin testing before employment is to detect those who require immunisation. As BCG immunisation within 25 years supported by a characteristic scar confers good immunity, only those without evidence of previous immunisation need 